\title{
British Southern Cameroons Health Services as an Appendage to Nigerian Health Sector, 1922-1961
}

\author{
${ }^{1}$ Canute A. Ngwa, ${ }^{2}$ Christian Asongwe* \\ ${ }^{1}$ Associate Professor of History University of Bamenda \\ ${ }^{2}$ University of Bamenda
}

\begin{abstract}
The incidence of disease on the colonial agenda triggered the development of healthcare services by colonial administrations in Africa. In Southern Cameroons, the British administration fashioned a medical policy whose implementation spanned from 1922 to 1930. Informed by the colonial imperative, administrative and medical officers developed medical infrastructure, trained and engaged personnel, conducted research, and made efforts to roll back the incidence of various diseases. This took curative and preventive forms in a context of conflicting agendas, colonial arrogance, cultural ignorance, and defective infrastructure and personnel. The outcomes were beneficial to the colonial enterprise and detrimental to the economic wellbeing of the local population, the incidental benefits notwithstanding.
\end{abstract}

Keywords: Southern Cameroons, Appendage, Nigerian Health Institutions, Management and structural organization

\section{Introduction}

In an effort to abide to the League of Nations' Mandate Agreement which, in part, instructed Britain to improve on the health of Southern Cameroonians, Britain, with hindsight from the failure of the Germans to address health problems, developed a new healthcare scheme for Southern Cameroons. The scheme which was still on paper came with the need for the organization of the health sector. The organizational structure of the healthcare system constituted an integral part of the general colonial administrative structure of Southern Cameroons. The territory was administratively attached to Nigeria. The implication of this was that all administrative services in Southern Cameroons were connected with similar services in neighbouring Nigeria. Broadly speaking, the colonial government was organised into technical departments or services: educational, agricultural, medical etc. Each performed a specific technical function. The medical department was an important unit of the administration and was in charge of the medical and health services in the territory. Hence, the healthcare system of Southern Cameroons fell under the Medical Department. It is important to stress that the organizational structure of this department along with its operation mechanism was dynamic, depending on the administrative reforms that occurred in both Nigeria and Southern Cameroons.

Since Southern Cameroons was governed as an integral part of Southern Nigeria during the Mandate Period, a health care system that was coordinated from Nigeria was established in the territory. In fact, public health in Southern Cameroons during the mandate period, as Forkusam observes, was the preserve of the Director of Medical and Sanitary Services (DMSS) who was based in Lagos, Nigeria. ${ }^{1}$ Under him were medical doctors, dispensaries attendants, nurses, dressers, vaccinators and sanitary inspectors whose role was to ensure the functioning of the health care system in Nigeria and Cameroons. Consequently, the Southern Cameroons Medical Department was directly responsible to the medical headquarters in Lagos, Nigeria. On its part, the Medical and Sanitary Department in Nigeria was attached to the West African Medical Service (WAMS) established in 1902, as an appendage of the Colonial Service, by the colonial government to deal

\footnotetext{
${ }^{1}$ A. L. Forkusam, "The Evolution of Health Services in the Southern Cameroons under British Administration 1916-1945”, DES Dissertation in History, University of Yaounde, 1978.
} 
with medical problems of its nationals who resided in British colonies. ${ }^{2}$ This was an unparalleled extension of the model of the imperial medical service in British India. But the medical services in West Africa were hastily conceived and, therefore, imperfect and inadequate during much of the colonial period. The medical service in British West Africa operated departments in each British colony including Nigeria ${ }^{3}$, which served the Southern Cameroons as long as the territory was part of the Nigerian Federation. As provided for by the administrative procedure, the DMSS in Nigeria issued regulations and instructions on medical and health matters to the Southern Cameroons Resident in Buea for onward transmission to the Medical Department in Victoria. ${ }^{4}$ The administrative procedure provided that such medical information should get to the Medical Department in Victoria through the District Officer or any other administrative channel.

\section{Organization and Functioning of British Southern Cameroons Medical Institutions Prior to the Second World War}

In Southern Cameroons there was a Medical Department headed by a Senior Medical Officer (SMO) who was stationed in Victoria and was charge with the implementation of decisions taken by the DMSS in Lagos, Nigeria. ${ }^{5}$ The town of Victoria was the medical administrative headquarters of Southern Cameroons. The health care system in the territory, just as in Nigeria, was intended to fight against diseases and unhygienic conditions all in the hope of improving the health of the people. Consequently, it was the responsibility of the SMO to design medical policies for the territory, supervise all aspects of medical work, and ensure the conduct of research and training. To put it differently, the staffs of the Medical Department were commissioned by their bosses in Nigeria to provide staff and hospitals for the territory, conduct and oversee medical field work, launch campaigns against epidemics, ensure the sanitation of townships and government stations, and engage in mental health and health propaganda. In an attempt to meet this goal, Southern Cameroons was initially divided into four medical administrative districts that corresponded to the four divisions the territory had at the time. The medical administrative districts were Victoria, Kumba, Mamfe and Bamenda. In each of these medical districts was stationed a Medical Officer who managed the healthcare system in his area of jurisdiction. ${ }^{6}$ These four medical officers with health administrative functions received and implemented instructions on medical and health matters from hierarchy in Victoria through the District Officers. It was also the medical officers' responsibility to transmit such information to their staff and collaborators, especially Native Authorities and Mission Agencies. This is indicative that private actors in the healthcare sector were all subject to the Medical Officer in the divisions where they carried out healthcare delivery activities. Indeed, the Medical Officers worked collaboratively with paramedical staff like European Nursing Sisters, Senior Nurses, Midwives, N.A. Dispensers and Dressers, as well as Sanitary Officers and mission medical staff. The Medical Officers prepared medical reports based on the information they received from their subordinates and collaborators in their respective divisions. Such reports, which quite often, included a rubric on suggestions were sent to the Senior Medical Officer in Victoria through the District Officers and Resident respectively. On his part, the Senior Medical Officer exploited the reports from the Medical Officers to produce a comprehensive report on Southern Cameroon's healthcare situation. Such a detailed report was then forwarded to the DMSS in Lagos, Nigeria through the office of the Resident in Buea.

The foregoing shows the organization of healthcare system in Southern Cameroons during the Mandate era. It reveals that medical work was inbuilt into the colonial administration of the territory. It constituted one of the administrative departments of this administration that was tied to Nigeria. This department was hierarchically structured in descending order from the Medical Services Department in Lagos to the Medical Officers in the Southern Cameroons' four divisions at the time. This hierarchical health administration

\footnotetext{
${ }^{2}$ F.M.Mukake, "Public Health and Public Health Management in British Southern Cameroons", 1922-1961, the Case of Victoria Division, MA Dissertation in History, University of Buea, 2011.

${ }^{3}$ Ralph Schram, A History of the Nigerian Health Services, Ibadan, Ibadan University Press, 1971.

${ }^{4}$ NAB, File No. Sc/1928/3, Hospital fees: General Correspondence for the procedure in medical correspondence ${ }^{5}$ Ibid

${ }^{6}$ V. J. Ngoh, History of Cameroon Since 1800, Limbe, Presbook, 1996
} 
structure which is relevant to the understanding of the healthcare system in Southern Cameroons is illustrated in diagram 1 below.

\section{Diagram 1: Organizational Structure of the Healthcare System, 1922-1946}

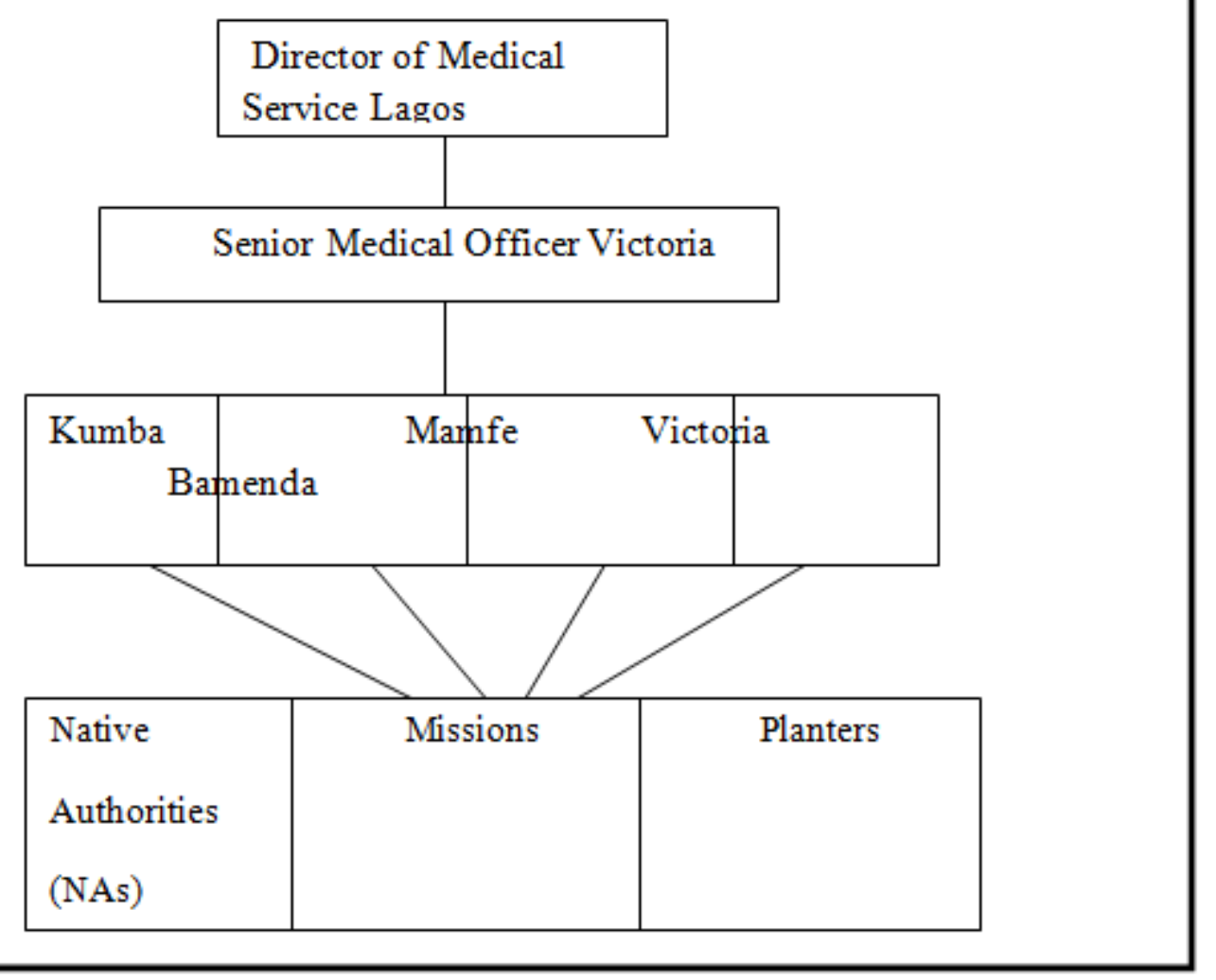

\section{Source: compiled by Author from Archival Documents}

In sum, the medical administrative structures of the Southern Cameroons healthcare system that were charged with the improvement of the health of the local population were connected with similar structures in Nigeria. But this Nigerian connection along with Britain's masked intention of using the healthcare system in meeting colonial ambitions placed medical services in a bad course. From 1946, however, the administrative changes in Nigeria that came through successive constitutional reforms in an era of heightened nationalist struggle amounted to changes in the organization of Southern Cameroons' medical department. These organizational mutations are worth revealing given their indispensability in informing analysis on the healthcare system after the Second World War.

\section{Changes in the Nigerian Medical Sector after the Second World War and their Impact on Southern Cameroons Medical Institutions}

The 1940s and 1950s was a period of dramatic changes in the entire administration of British Southern Cameroons. The termination of military operations in 1945 officialised the demise of the League of Nations together with its Mandate System. The creation of the United Nations in 1945 from the ruins of the League of Nations came with a new international status for Southern Cameroons. This was the trusteeship status that was provided by Article 76b of the United Nations Charter. In 1946, Southern Cameroons was part of the British Cameroon that became a Trust Territory of the United Nations under the administration of Britain. ${ }^{7}$ The Trusteeship Agreement that sanctioned this transition, maintained Britain's health development assignment, and improved on the supervision guidelines. This time around, the UN had to be sending visiting missions to Southern Cameroons as well as receive petitions from the people relating to how the British were administering the territory. Although the reforms did not end Southern Cameroons' administrative attachment to Nigeria, they caused Britain to timidly accept the responsibility of providing medical care as a statutory service. Perhaps, this was one of the things that necessitated the reorganization of the medical service department.

${ }^{7}$ V. J. Ngoh, History of Cameroon Since 1800, Limbe, Presbook, 1996 
The first changes came in 1947 when the Richard's Constitution divided Nigeria into three administrative regions, namely, Northern, Western and Eastern regions of Nigeria. This made Southern Cameroons to be administratively attached to the newly created Eastern Region of Nigeria. ${ }^{8}$ For the first time, therefore, the territory's healthcare system was governed from Enugu, the Eastern Regional headquarters. This made the Senior Medical Officer to now be directly answerable to the Director of Medical Services for the Eastern Region who was stationed at Enugu. Accordingly, direct subordination to the central medical department in Lagos was terminated. This facilitated visits by medical staff from Enugu to Southern Cameroons and vice versa. Almost at the same time, the Cameroon Development Corporation which had just been created became a key participant in medical service delivery. The medical department of this corporation had to be organized on the basis of existing regulations and included in the organigramme of the medical department.

In 1949 when Southern Cameroons was reorganised into two provinces with each having three divisions, the structure of the medical department witnessed new changes. The two provinces were the Cameroon Province which was divided into Kumba, Mamfe and Victoria divisions and the Bamenda Province that comprised Bamenda, Wum and Nkambe as divisions. This administrative reorganization affected the administrative structure of the medical service in three ways. First, there was a change in the title and status of the medical administrator of the territory. Due to the creation of the two provinces, the territory that was formerly administered medically by a Senior Medical Officer now became the responsibility of the Principal Medical Officer still with headquarters in Victoria. ${ }^{9}$ This expectedly made the Principal Medical Officer the direct link between Southern Cameroons and the Eastern Regional medical boss. Second, the reforms made Southern Cameroons to now have two Senior Medical Officers stationed in the two provinces. The implication was that Bamenda and Victoria, in their capacity as provincial capitals, gained the status of provincial medical administrative headquarters. Third, for the first time, Southern Cameroons was divided into six medical districts that corresponded to the six divisions the territory now had. This was beneficial to the improvement and extension of medical services and staff in the territory.

\section{Management}

As healthcare services were being provided under the new administrative framework, nationalist activities intensified, with an almost unanimous call for the territory to be given a regional status with its own political, educational, health and economic structures just like the other three Nigerian regions. On October 1, 1954, after a tortuous journey, these changes finally came as Southern Cameroons ceased to be a part of the Eastern Region and acquired a large measure of autonomy as a Quasi Region. The 1954/55 Annual Medical Report sees this semi-autonomy status as an underlying factor for the further reorganization of the medical department in Southern Cameroons. ${ }^{10}$ This is true given that the political changes provided the territory with structures such as the Southern Cameroons House of Assembly, an Executive Council and various administrative services. It is important to state that both the Assembly and Executive Council could debate and take decisions on matters relating to health. For instance, the Executive Council comprised four ministerial departments. One of such ministries which was headed by Reverend J. C. Kangsen addressed health matters and other issues. ${ }^{11}$

Certainly, the powers of the Principal Medical Officer, who by these changes now became answerable first to Rev. Kangsen and, once more, to the DMSS in Lagos, were strengthened. As the 1954/55 medical report states, "the Principal Medical Officer ... is responsible for the medical administration of the territory and enjoys a status similar in most respect to that of a Regional Director of Medical Services" 12 In his new capacity as a federal regional medical administrator, the Principal Medical Officer had direct links with Lagos. However, given that the political independence of October 1954 could not be matched by independence in the medical field, as was the case with other fields, Southern Cameroons continued to depend entirely on Lagos and the regions for the training of its medical and health staff with the exception of nurses, community nurses and Grade II midwives.

\footnotetext{
${ }^{8}$ Ibid

${ }^{9}$ Interview with Ejang Martha, 83 years, Retired Nurse, Kumba, 4 November 2016.

${ }^{10}$ NAB, File No. B.99/Vol. III, Annual Medical Report, 1954/55.

${ }^{11}$ Interview with Elias Toh, 86 Years, Retired Administrator, BBH, Nso, 4October 2016.

${ }^{12}$ NAB, File No. B.99/Vol. III, Annual Medical Report, 1954/55.
} 
To this hierarchical medical administrative structure should be added the Medical Field Unit in Kumba. Besides, the political reforms of 1954 came at a time when the medical authorities of the Eastern Region at Enugu were reflecting on putting in place Hospital Advisory Boards (HAB). This was the outcome of a Senior Medical Officers' Conference that was held at Enugu on 29 March 1954. This initiative was intended to ease the liaison between the public and hospital management. ${ }^{13}$ In August 1954, two months to Southern Cameroons' attainment of a Quasi Regional status, the Director of Medical Services, Enugu, released a medical circular instructing that all hospitals should have a HAB for the purpose of improving the relationship between the hospitals and their patients and to encourage the public to take a healthy interest in their local hospitals. These advisory boards which became included in Southern Cameroons' medical organigramme comprised the District Officer of the area where the hospital was located as Chairperson, the Medical Officer as Secretary, the most senior Nurse, the Pharmacist and four representatives of the local population. Among other things, the HAB's role was to advise the hospital administration on the improvement of the medical services provided by the hospital, answer questions and criticisms from the public arising out of the administration of the hospital and to advise on any other matter which may be referred to it by a member of the public. When Southern Cameroons gained a Quasi Regional status in October 1954, the Principal Medical Officer for the territory took measures to create HABs in the six divisions the territory had at the time.

In 1955, due to allegations of heightened corruption and extortion among the staff of government hospitals, Hospital Visiting Committees (HVCs) were instituted. This began in March 1955 when some members of the Southern Cameroons House of Assembly accused hospital staff for indulging in corruption. ${ }^{14}$ This caused the Executive Council and the Principal Medical Officer to hold consultation meetings on how to roll back corruption in the hospitals. What emerged from these consultations that were chaired by Rev. J. C. Kangsen was the decision to create Hospital Visiting Committees to add to the already existing HABs. The Visiting Committees comprised of members drawn from the local population. Such members had to be people willing to take interest in the affairs of the hospital, particularly the welfare of the patients. ${ }^{15}$ Its terms of reference provided that the committee should meet the medical doctor in charge of the hospital from time to time and help him by bringing to his attention any unsatisfactory state of affairs which he might be in a position to correct. The committee was therefore expected to report cases of extortion to the doctor. This reform was quickly implemented in the divisions that already had hospitals.

\section{The Post War Structural organization}

Generally, a new Southern Cameroons medical organization emerged from the reforms spanning from 1946 to 1955. According to this organization as of 1955, Southern Cameroons severed medical administrative links with the Eastern Region of Nigeria as its medical service once more obtained direct administrative links with the Nigerian Medical Department in Lagos. At the level of Southern Cameroons, the Principal Medical Officer administered the territory's medical and health services, still from the medical administrative headquarters, Victoria. He was assisted at this central service level by senior service staff and the Victoria divisional medical corps that was headed by the Medical Officer. The two administrative provinces of Cameroon and Bamenda were each headed by a Senior Medical Officer. The Senior Medical Officer was to oversee and supervise medical work in the entire province. The divisions within the provinces were medically administered by Medical Officers who were answerable to the Senior Medical Officers. In the Cameroon Province, there were Medical Officers in the Victoria, Kumba and Mamfe divisions. Similarly, the Bamenda, Wum and Nkambe divisions of the Bamenda Province were each placed under a Medical Officer. This administrative organization of the health sector reveals that each province was broken up into Medical Areas whose boundaries were conterminous with the divisional boundaries. It should be noted that the medical activities of missions, commercial enterprises such as the CDC, the Native Authorities and other volunteer agencies were controlled by the Principal Medical Officer, most often through the Senior Medical Officers and Medical Officers, mainly in an advisory capacity. There was a Medical Field Unit in Kumba, Hospital Advisory Boards and Hospital Visiting Committees in the divisions that had hospitals. This reformed medical administrative structure is well illustrated in diagram 2.

\footnotetext{
${ }^{13}$ NAB, File No. B. 3/30, Minutes of Senior Medical Officers' Conference, Enugu, 29 March 1954.

${ }^{14}$ NAB, File No. B. 3/30, Hospital Visiting Committees.

15 Ibid
} 


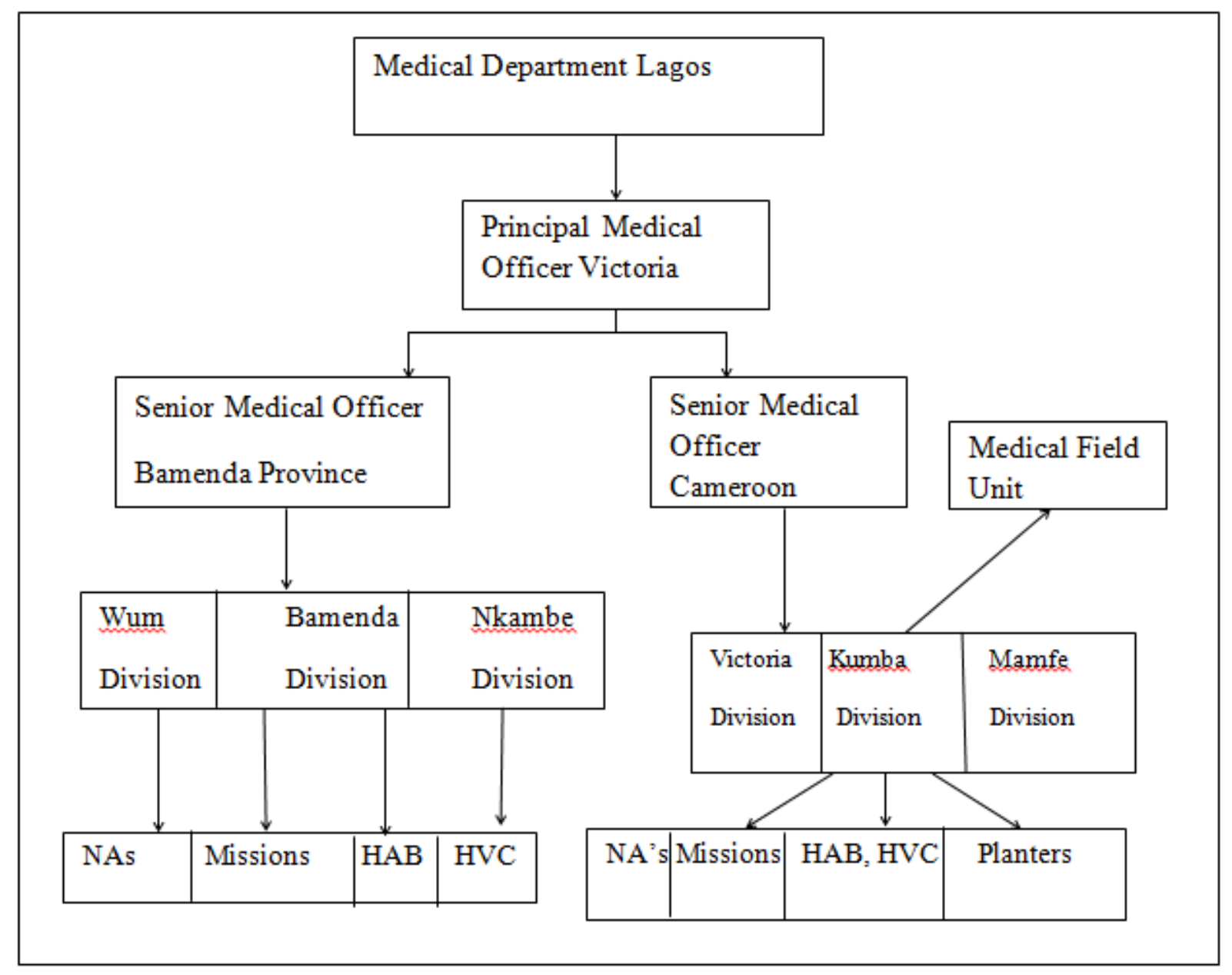

\section{Source: Compiled by Author from Archival Documents}

The foregoing diagram illustrates the plethora of hierarchical structures that were put in place for Southern Cameroons' medical administration. The health governing bodies were manned by colonial healthcare officials who were expected to have a genuine sympathy for the sick and a wish to relieve their suffering. The healthcare officials who constantly reflected on the reformation of the medical administrative system throughout the Mandate and Trusteeship periods were, according to public declarations at the time, concerned about the various diseases that occurred in endemic and epidemic forms in Southern Cameroons. The dynamic medical administrative structure that has been discussed reveals that both government and private actors were engaged in the implantation of the colonial healthcare system fashioned for Southern Cameroons by British healthcare officials.

\section{Conclusion}

This paper has examined the operational mechanism of Southern Cameroons' health care system from a double perspective: policy and structure. This was intended to ease the understanding of how health care was planned, developed and implemented in Southern Cameroons in a bid to improve the healthcare situation of the populations. The paper begins with an examination of the context of the health care system in the territory by highlighting the various factors that combined to provoke the need for healthcare development. Arguably, the British health care system came as a response to the health development obligations enshrined in the Mandate Agreement as well as Britain's desire to further its colonial interests in the territory. The paper reveals that the healthcare policies that had been fashioned for Nigeria were simply extended to British Southern Cameroons since the territory, for administrative convenience, had been appended to the Eastern Region of Nigeria. Accordingly, all health ordinances and regulations that had govern the health sector in Nigeria were simply applied to corresponding structures in Southern Cameroons with very little modifications. Overall, the paper submits that despite the provisions of the Mandate Agreement requiring Britain to develop a healthcare system capable of surmounting the health needs of 
Southern Cameroonians, the underlying policy and structures of the healthcare system during British colonial rule were informed and shaped by the need for her to fulfill her broader colonial ambitions.

\section{References}

[1.] Aka, Emmanuel Aloangamo, The British Southern Cameroons, 1922-1961: A study in colonialism and under development, Platteville, Nkemnji Global Tech, 2002.

[2.] Asongwe, Christian. "Health Care Delivery in British Southern Cameroons 1922-1961: An Historical Evaluation", Unpublished Phd Thesis in History, University of Yaoundé I, 2018

[3.] Forkusam, Austin Langmia, "The Evolution of Health Services in the Southern Cameroons under British Administration 1916-1945", DES Dissertation in History, University of Yaounde, 1978.

[4.] Gelfand, M., Tropical Victory: An Account of the Influence of Medicine on the History of Southern Rhodesia, 1890-1923, Cape Town, Juta, 1953.

[5.] Mukake, Flavours M. "Public Health and Public Health Management in British Southern Cameroons", 1922-1961, The Case of Victoria Division,Unpublished MA Dissertation in History, University of Buea, 2011.

[6.] Ncube, G., "The Making of Rural Healthcare in Colonial Zimbabwe: A History of the Ndanga Medical Unit, Fort Victoria, 1930-1960s", PhD Thesis in History, University of Cape Town, 2012.

[7.] Nehtegha, T., "Health Services in Bamenda Division", DIPES II Dissertation in History, HTTC

Bambili, 2014

[8.] Ngoh. Victor Julius, Southern Cameroons 1922-1961; A Constitutional History, Burlingston USA, Ashgate, 2001.

[9.] --------- History of Cameroon Since 1800, Limbe, Presbook, 1996.

[10.] Ransford, O., Bid the Sickness Cease: Disease in the History of Black Africa, London, John Murray, 1983.

[11.] Ralph Schram, A History of the Nigerian Health Services, Ibadan, Ibadan University Press, 1971.

[12.] Roberts, J., Sharing the Burden of Sickness: A History of Healing in Accra, Gold Coast, $1677-$ 1957',

[13.] Tebo, T.N., "Public Sanitation in the British Southern Cameroons 1922-1961: A Historical Evaluation", DIPES II Dissertation in History, HTTC Bambili, 2014. National Archive Buea (Cameroon)

- File No. B. 3/30, Minutes of Senior Medical Officers' Conference, Enugu, 29 March 1954.

- File No. B.99/Vol. III, Annual Medical Report, 1954/55 .

- File No. B. 3/30, Hospital Visiting Committees

- File No. Sc/1928/3, Hospital fees: General Correspondence for the procedure in medical correspondence 